\title{
Eficiência simbiótica de estirpes de Bradyrhizobium isoladas de solo do Cerrado em caupi
}

\author{
Jerri Édson Zillii(1), Romano Roberto Valicheski(2), Norma Gouvêa Rumjanek(3), Jean Luis Simões-Araújo(3), \\ Francisco Rodrigues Freire Filho ${ }^{(4)}$ e Maria Cristina Prata Neves ${ }^{(3)}$
}

\begin{abstract}
(1)Embrapa Roraima, BR 174, Km 8, CEP 69301-970 Boa Vista, RR. E-mail: zilli@cpafrr.embrapa.br (2)Universidade Estadual do Norte Fluminense, Av. Alberto Lamego, no 2.000, CEP 28015-620 Campos dos Goytacazes, RJ. E-mail: valicheski@uenf.br (3)Embrapa Agrobiologia, BR 465, Km 7, CEP 23890-000 Seropédica, RJ. E-mail: norma@cnpab.embrapa.br, jean@cnpab.embrapa.br, mcpneves@embrapa.br (4)Embrapa MeioNorte, Av. Duque de Caxias, no 5.650, CEP 64006-220 Teresina, PI. E-mail: freire@cpamn.embrapa.br
\end{abstract}

\begin{abstract}
Resumo - O objetivo deste trabalho foi avaliar as relações filogenéticas de estirpes de Bradyrhizobium e a contribuição destas estirpes para a fixação biológica de nitrogênio em caupi, em solos do Cerrado. Na avaliação da relação filogenética, o gene $16 \mathrm{~S}$ rDNA de cada uma das estirpes foi amplificado e seqüenciado, e para a análise da eficiência simbiótica, determinou-se: $\mathrm{N}$ total, matéria seca das plantas, massa de nódulos e redução de acetileno, em casa de vegetação, e ocupação nodular, em experimento de campo. A maioria das estirpes estudadas pertence a $B$. elkanii e, pelo menos dez das estirpes, independentemente da espécie, apresentaram bom desempenho quanto à fixação biológica de $\mathrm{N}_{2}$. As estirpes BR3262, BR3280 (caracterizadas como B. elkanii) e BR3267, BR3287 e BR3288 (Bradyrhizobium sp.) mostram-se como inoculantes potenciais para o caupi, em razão do bom desempenho tanto na eficiência simbiótica quanto na ocupação nodular.
\end{abstract}

Termos para indexação: fixação biológica de nitrogênio, 16S rDNA, Bradyrhizobium, Bradyrhizobium elkanii.

\section{Symbiotic efficiency of cowpea Bradyrhizobium strains in Cerrado soils}

\begin{abstract}
The obejctive of this study was to evaluate the phylogenetic relationships of Bradyrhizobium strains, and the contribution of these strains to cowpea biological nitrogen fixation in Cerrado soils. To elucidate the phylogenetic relationships among strains, their $16 \mathrm{~S}$ rDNA gene was extracted, amplified and sequenced. In order to evaluate the symbiotic efficiency, total $\mathrm{N}$, plant dry matter, nodular mass and acetylene reduction in a greenhouse experiment, and nodular occupation, in a field experiment, were determined. Most part of the strains belonge to B. elkanii, and at least ten of the analyzed strains, independently of the species, presented high capacity to fix $\mathrm{N}_{2}$. The strains BR3262, BR3280 (characterized as B. elkanii), BR3267, BR3287 and BR3288 (Bradyrhizobium sp.) exhibit a potential as inoculant for cowpea, due to their high biological nitrogen fixation.
\end{abstract}

Index terms: biological nitrogen fixation, 16S rDNA, Bradyrhizobium, Bradyrhizobium elkanii.

\section{Introdução}

No Brasil, o caupi (Vigna unguiculata (L.) Walp.) é cultivado, basicamente, em regime de subsistência, nas regiões Norte e Nordeste, principalmente por sua adaptação às condições edafoclimáticas. Nessas regiões, esta cultura desempenha um papel importante na alimentação e na geração de empregos para a população de baixa renda. Segundo Freire Filho et al. (1999), a cultura do caupi no Brasil gera, anualmente, cerca de 2,4 milhões de empregos diretos, além de compor a dieta de pelo menos 27,5 milhões de pessoas.
O caupi tem sido introduzido, recentemente, também em áreas de grandes produtores agrícolas nos Cerrados dos Estados do Piauí e Maranhão, principalmente por sua compatibilidade com o sistema de rotação de cultura e o regime pluviométrico regional. Nessas áreas, os agricultores introduzem o caupi na "safrinha", após a colheita do arroz, no final da estação das chuvas, tanto em lavouras recém-abertas, como em rotações de cultivos bianuais com soja. Nessas condições, o caupi desenvolve-se bem, com regime pluviométrico decrescente e, ainda, utiliza os nutrientes residuais da cultura do arroz, garantindo uma renda extra aos agricultores. 
O caupi é uma espécie de grande valor genético e possui genes de resistência a estresses, que lhe conferem ampla adaptação edafoclimática, alto potencial produtivo e alta capacidade de obter $\mathrm{N}$ em associação com bactérias do gênero Bradyrhizobium (Bezerra, 1997; Ehlers \& Hall, 1997; Xavier, 2000). Por causa de sua importância agronômica, é uma das espécies vegetais estudadas na estação espacial da Nasa (Ehlers \& Hall, 1997).

O N é um dos nutrientes mais limitantes à produção de cereais nas regiões de clima tropical, e sua fixação biológica (FBN) é importante para a produção vegetal. Um dos exemplos mais bem sucedidos de FBN é o caso da soja no Brasil, onde a utilização de inoculantes com Bradyrhizobium tem proporcionado uma economia anual de US\$ 3 bilhões, em fertilizantes nitrogenados (Hungria et al., 2005).

No caso do caupi não há uma estimativa, em termos econômicos, da contribuição da FBN. No entanto, sabese que é importante para manter a produtividade das lavouras de subsistência, em que a adubação nitrogenada mineral não ocorre (Martins et al., 2003). Em termos de quantidade de $\mathrm{N}_{2}$ fixada, existem dados que indicam contribuições superiores a $100 \mathrm{~kg} \mathrm{ha}^{-1}$, embora esses valores sejam variáveis, especialmente em avaliações de campo (Wani et al., 1995). Este fato tem sido relacionado, principalmente, com a promiscuidade da simbiose entre plantas de caupi e estirpes de rizóbio nativas dos solos tropicais (Neves \& Rumjanek, 1997).

A associação de plantas de caupi com estirpes de rizóbio apresenta baixa especificidade; há relatos da associação com pelo menos seis espécies de rizóbio: B. japonicum (Jordan, 1982), B. elkanii (Kuykendall et al., 1992), Sinorhizobium fredii (Lajudie et al., 1994), S. xinjiangensis (Chen et al., 1988), Rhizobium hainanense (Chen et al., 1997) e $R$. tropici IIA (Zilli, 2001), além de outras estirpes de Bradyrhizobium cujas espécies não foram identificadas (Martins, 1996).

Os estudos de FBN em caupi têm focado principalmente as espécies B. japonicum e B. elkanii, pelo fato delas apresentarem maiores contribuições para a FBN, na maioria das leguminosas herbáceas, em regiões de clima tropical (Moreira \& Siqueira, 2002). No caso da cultura da soja, a melhor capacidade de competir por sítios de nodulação no campo tem sido atribuída à espécie B. elkanii (Boddey \& Hungria, 1997; Neves \& Rumjanek, 1997). Porém, quanto ao acúmulo de N, tem sido verificada maior eficiência promovida por
B. japonicum (Teaney \& Fuhrmann,1992; Neves \& Rumjanek, 1997).

O objetivo deste trabalho foi avaliar a contribuição de estirpes do gênero Bradyrhizobium, isoladas de nódulos de caupi cultivado em solo de Cerrado, para a FBN nesta cultura e, também, a relação filogenética entre estas estirpes.

\section{Material e Métodos}

Foram utilizadas as estirpes: BR3277, BR3278, BR3279, BR3280, BR3281, BR3283, BR3284, BR3285, BR3286, BR3287 e BR3288, isoladas de raízes de plantas de caupi, cultivadas em solo de Cerrado do Estado do Piauí (Zilli, 2001); a BR3267, isolada do Semi-Árido do Estado de Pernambuco (Martins, 1996); a BR3262, isolada do Sistema Integrado de Produção Agroecológica (SIPA) em Seropédica, RJ (Zilli et al., 1998); e a estirpe BR2001, recomendada até recentemente pela rede de laboratórios para recomendação, padronização e difusão de tecnologia de inoculantes microbiológicos de interesse agrícola (Relare), para a inoculação na cultura do caupi.

O gene 16S rDNA dessas estirpes foi amplificado através da reação em cadeia da polimerase (PCR) (Zilli, 2001), utilizando-se os iniciadores Y1 e Y3 (Young et al., 1991). O produto da PCR foi, então, purificado com o kit Wizard Miniprep (Promega) e seqüenciado em seqüenciador de DNA automático MegaBACE1000 (Amersham Bioscience), utilizando-se os iniciadores Y1 e Y3 e seis iniciadores intermediários distribuídos ao longo das 1.500 bases do gene.

As seqüências obtidas foram depositadas no GeneBank com os números de acesso AY649429 (BR2001), AY649430 (BR3262), AY649439 (BR3267), AY649431 (BR3277), AY649432 (BR3278), AY649433 (BR3279), AY649434 (BR3280), AY649435 (BR3281), AY649436 (BR3283), AY649437 (BR3284), AY649438 (BR3285), AY649441 (BR3286), AY649442 (BR3287) e AY649440 (BR3288).

As seqüências das estirpes ATTC49852 (estirpe referência de B. elkanii), ATCC10324 (estirpe referência de B. japonicum), ATCC700350 (estirpe referência de B. liaoningense), SEMIA 587 e SEMIA 5019 (29W) (estirpes de B. elkanii recomendadas para a cultura da soja no Brasil), e SEMIA 5079 (CPAC-15) e SEMIA 5080 (CPAC-7) (estirpes de B. japonicum recomendadas para a cultura da soja no Brasil) foram 
obtidas do GeneBank e utilizadas para a comparação filogenética.

Para determinação do acúmulo de $\mathrm{N}$, da produção de matéria seca, e para avaliação da nodulação, foi realizado um experimento em casa de vegetação, nos meses de outubro e novembro de 1999. O delineamento experimental utilizado foi o de blocos ao acaso, com cinco repetições. Utilizou-se um tratamento controle, isento de inoculante e $\mathrm{N}$, e uma testemunha nitrogenada (25 mg de $\mathrm{N}$ por vaso por semana, na forma de $\mathrm{NH}_{4} \mathrm{NO}_{3}$ ) isenta de inoculante. O cultivo das plantas foi realizado em vasos Leonard (Vincent, 1970), com areia e vermiculita (2:1) estéreis. As sementes de caupi, cultivar BR17, foram lavadas com etanol por 30 segundos, desinfestadas com hipoclorito de sódio 5\%, por $3 \mathrm{mi}-$ nutos, e lavadas com água esterilizada por 10 vezes, sucessivamente.

A semeadura foi realizada diretamente nos vasos, com 3 sementes por vaso, e após a germinação deixou-se apenas uma planta por vaso. A inoculação foi realizada três dias depois da germinação das plantas, tendo-se aplicado $1 \mathrm{~mL}$ do inoculante (aproximadamente $10^{8}$ unidades formadoras de colônias) no colo das plantas. Os nutrientes foram fornecidos às plantas, semanalmente, na forma de solução nutritiva Norris e Döbereiner: $\mathrm{KCl}, 2 \mathrm{mM}$; $\mathrm{K}_{2} \mathrm{HPO}_{4}$, 0,3 mM; $\mathrm{KH}_{2} \mathrm{PO}_{4}$, 0,7 mM; $\mathrm{CaSO}_{4} \cdot 5 \mathrm{H}_{2} \mathrm{O}, 0,3 \mu \mathrm{M} ; \mathrm{ZnSO}_{4} \cdot 7 \mathrm{H}_{2} \mathrm{O}, 0,7 \mu \mathrm{M}$; $\mathrm{MnSO}_{4}, 1 \mu \mathrm{M}$; $\left(\mathrm{NH}_{4}\right)_{6} \mathrm{Mo}_{7} \mathrm{O}_{24} .4 \mathrm{H}_{2} \mathrm{O}, 0,002 \mu \mathrm{M}$; $\mathrm{H}_{3} \mathrm{BO}_{3}, 11,5 \mu \mathrm{M} ; \mathrm{FeSO}_{4} .7 \mathrm{H}_{2} \mathrm{O}, 17,9 \mu \mathrm{M}$; ácido cítrico, $26 \mu \mathrm{M}$; em volume de $0,25 \mathrm{~L}$ por vaso, e a irrigação foi realizada com água destilada esterilizada, quando necessário.

Depois de 55 dias do plantio, no estádio de florescimento, as plantas foram colhidas, separando-se a parte aérea da raiz, na altura do nó cotiledonar. Na determinação da atividade da nitrogenase, utilizouse o método de análise de redução de acetileno (ARA) (Mague \& Burris, 1972), tendo-se incubado as raízes noduladas em acetileno $10 \%$, por 10 minutos, em recipientes de vidros hermeticamente fechados. Após este período, coletou-se $1 \mathrm{~mL}$ de gases do interior dos recipientes, e detectou-se o etileno produzido, em um cromatógrafo gasoso com detecção por ionização de chama. Posteriormente, os nódulos, as raízes e a parte aérea das plantas foram secados em estufa, a $60^{\circ} \mathrm{C}$ por 72 horas, e pesados. Depois da pesagem, a parte aérea foi moída para a determinação do $\mathrm{N}$ total, pelo método semimicro Kjeldahl (Liao, 1981).
A avaliação da ocupação nodular em plantas de caupi, no campo, foi realizada entre os meses de fevereiro e março de 2000, em área de produtor rural, no Município de Baixa Grande do Ribeira, PI, coincidindo com a época de plantio do caupi na região. O delineamento experimental utilizado foi o de blocos ao acaso, com 3 repetições, com parcela de $5 \times 3 \mathrm{~m}$, com $2 \mathrm{~m}$ de bordadura. Utilizou-se a cultivar de caupi BR17 (recomendada para a região), com espaçamento de $50 \mathrm{~cm}$ entre linhas e $10 \mathrm{~cm}$ entre plantas. $O$ experimento constou de nove tratamentos, sendo sete estirpes de Bradyrhizobium (BR2001, BR3262, BR3267, BR3278, BR3280, BR3287 e BR3288), um tratamento com N na forma de uréia (100 $\left.\mathrm{kg} \mathrm{ha}^{-1}\right)$, aplicada $50 \%$ no plantio e $50 \%$ trinta dias depois, e um tratamento testemunha, sem sem nitrogênio e sem inoculante (controle).

O experimento recebeu adubação com $200 \mathrm{~kg} \mathrm{ha}^{-1}$ do formulado mineral NPK 0-40-6, conforme recomendação de cultivo na fazenda. O inoculante foi preparado cultivando-se as bactérias em meio YMA líquido (Fred \& Waksman, 1928), por 72 horas, e aplicação em turfa esterilizada (concentração final de $10^{8}$ unidades formadoras de colônias por grama do inoculante). A inoculação foi feita com $250 \mathrm{~g}$ de inoculante por $50 \mathrm{~g}$ de semente (De-Polli \& Franco, 1985).

Antes da semeadura do caupi coletou-se uma amostra de solo composta (dez amostras simples), de cada um dos blocos do experimento, para a determinação do número mais provável (NMP) de células de rizóbio, conforme o método descrito por Woomer (1994), utilizando-se o siratro (Macroptilium atropurpureum) como planta hospedeira.

Aos 35 dias, foi realizada a coleta de nódulos, retirando-se dez plantas, ao acaso, de cada parcela. Os nódulos foram, inicialmente, acondicionados em sílica gel (temperatura ambiente) até a completa desidratação. Posteriormente, retiraram-se dez nódulos, ao acaso, de cada uma das parcelas, para serem analisados por meio da reação de imunoadsorção com enzima acoplada (Elisa). Para esta reação, inicialmente, foram produzidos os anti-soros com as sete estirpes de Bradyrhizobium utilizadas neste trabalho, seguindose a metodologia proposta por Reis et al. (1997), adaptada por Ribeiro (1999), sendo os anti-soros purificados posteriormente em colunas HiTrap Protein A (Amersham), seguindo-se recomendação do fabricante. Os testes Elisa foram realizados em placas de poliestireno Hemobag de 96 poços (Hemobag Produtos Cirúrgicos), tendo-se seguido o protocolo descrito por Reis et al. (1997). 


\section{Resultados e Discussão}

Observa-se no agrupamento das estirpes de rizóbio, a partir da seqüência do 16S rDNA, que todas as estirpes apresentam mais de $98 \%$ de similaridade entre si (Figura 1). Nove das estirpes agruparam-se com a estirpe referência de B. elkanii (ATTC49852), e com SEMIA 587 e SEMIA 5019 (29W), que são estirpes de B. elkanii utilizadas como inoculante para a soja no Brasil e encontram-se amplamente dispersas nos solos brasileiros. Outras três estirpes agruparam-se com as estirpes padrões de B. japonicum (ATCC10324), B. liaoningense (ATCC700350) e as estirpes SEMIA 5079 (CPAC-15) e SEMIA 5080 (CPAC-7), que são as estirpes de $B$. japonicum recomendadas para inoculação em soja no Brasil. A estirpe BR3267 e especialmente a BR3285 agruparam-se de forma intermediária com B. elkanii e com o grupo de B. japonicum e $B$. liaoningense.

Estes resultados indicam que a maior parte das estirpes isoladas do solo do Piauí deve pertencer a B. elkanii, corroborando as investigações realizadas por Zilli et al. (2004), que utilizaram caracterização morfológica e análise de restrição do DNA ribossomal amplificado (ARDRA) do 16S rDNA, quando observaram predomínio de estirpes com características semelhantes a B. elkanii.

Com exceção das estirpes BR3262, BR2001 e BR3267, as estirpes deste trabalho foram obtidas em área de Cerrado, sob diferentes manejos agrícolas, inclusive áreas cultivadas com soja por vários anos, antes da coleta de solo para a captura do rizóbio (Zilli, 2001). Isto ressalta a possibilidade de algumas das estirpes terem sido introduzidas no solo por meio de inoculantes utilizados para soja, contendo as estirpes de B. elkanii SEMIA 5019 (29W) e SEMIA 587 ou de B. japonicum SEMIA 5079 (CPAC-15) e SEMIA 5080 (CPAC-7).

Ferreira \& Hungria (2002) estudaram a nodulação de soja, tratada com inoculantes provenientes de solos de áreas não cultivadas, e verificaram que mesmo em locais distantes de áreas produtoras de soja existem estirpes nodulantes, que possuem alta similaridade genotípica e fisiológica com estirpes atualmente utilizadas como inoculantes, o que indica a dispersão dessas estirpes via correntes de ar. Ainda não se tem certeza da existência de estirpes de Bradyrhizobium nativos no Brasil capazes de nodular soja (Ferreira \& Hungria, 2002).
O agrupamento das estirpes BR3286, BR3287 e BR3288, isoladas do Cerrado, tanto com B. japonicum quanto com $B$. liaoningense não deixa claro a qual espécie pertencem. Em virtude da freqüência de uso de inoculantes com estirpes de B. japonicum, e maior distribuição desta espécie no Brasil, há uma possibilidade maior de serem B. japonicum. No caso das estirpes BR3267, isolada de áreas semi-áridas (Martins, 1996), e BR3285, existe a possibilidade de não

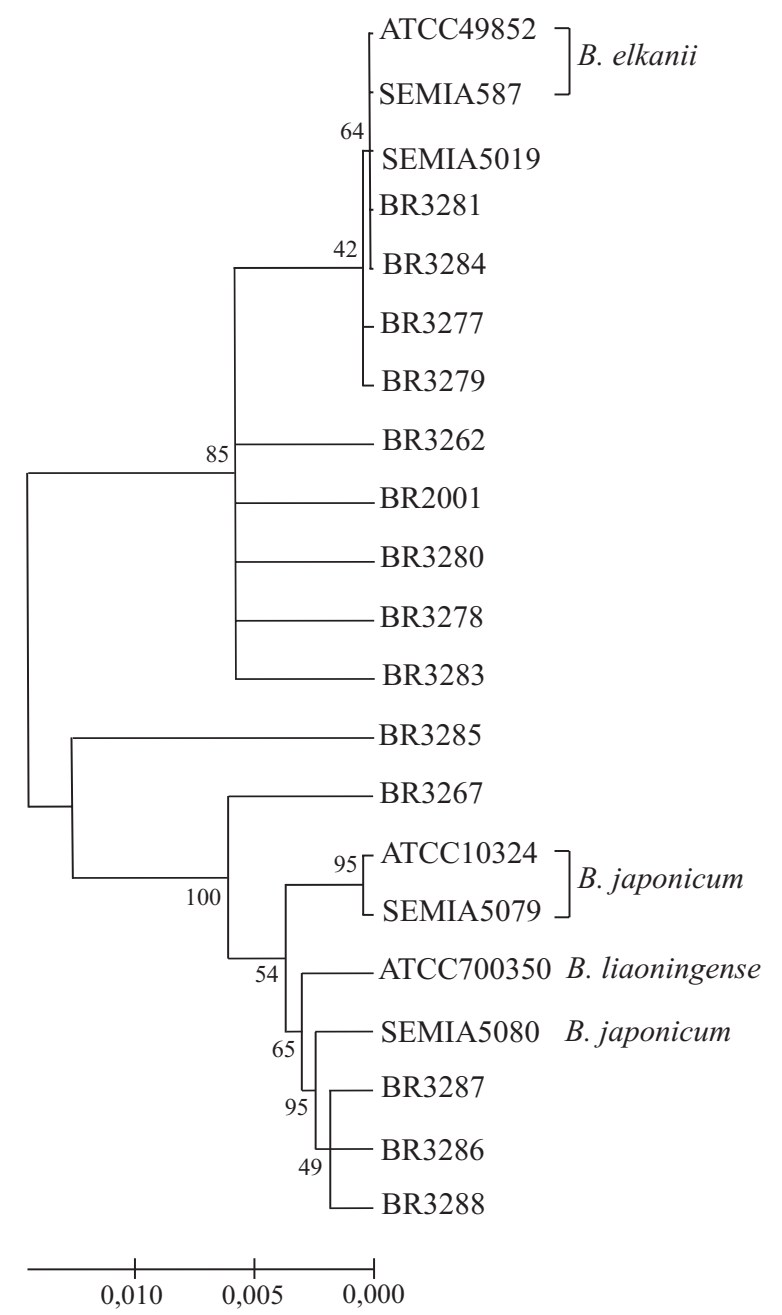

Figura 1. Dendrograma, método do vizinho mais próximo, mostrando a filogenia de estirpes de rizóbio, isoladas de caupi cultivado em solo de Cerrado, baseada na seqüência do $16 \mathrm{~S}$ rDNA. O alinhamento das seqüências foi realizado no programa Clustal W, e o dendrograma foi construído por meio do programa Mega v.2. Os números, na figura, indicam o número de vezes em que cada seqüência agrupou-se em determinada posição, durante a análise (bootstrap). 
pertencerem a nenhuma das espécies de Bradyrhizobium descritas até o momento, e podem compor uma nova espécie. De fato, existe uma lacuna no conhecimento das espécies de rizóbio que nodulam caupi e outras leguminosas de clima tropical, as quais são efetivamente noduladas por estipes identificadas apenas como Bradyrhizobium tropical ou Miscelânea caupi (Neves \& Rumjanek, 1997; Moreira \& Siqueira 2002). Assim, as estirpes BR3286, BR3287, BR3288, BR3267 e BR3285 serão referidas neste trabalho apenas como Bradyrhizobium sp.

As estirpes BR2362 e BR3267 proporcionaram acúmulo de $\mathrm{N}$, na parte aérea das plantas de caupi, $15 \%$ maior quando comparado ao tratamento com a estirpe BR2001 (estirpe recomendada como inoculante comercial para a cultura do caupi), e estatisticamente superior a seis tratamentos com inoculação, além do tratamento com $\mathrm{N}$ e do controle (Tabela 1 ). Sete das estirpes testadas propiciaram acúmulo de $\mathrm{N}$ que não diferiu, significativamente, do tratamento que recebeu $25 \mathrm{mg}$ de $\mathrm{N}$ por vaso por semana. Apenas três tratamentos tiveram acúmulo significativamente inferior à estirpe BR2001.

Tabela 1. Matéria seca total, nitrogênio total acumulado na parte aérea, massa de nódulos secos e análise de redução de acetileno (ARA), de plantas de caupi com inoculação de estirpes de Bradyrhizobium spp., isoladas de solo de Cerrado do Piauí ${ }^{(1)}$.

\begin{tabular}{|c|c|c|c|c|}
\hline Estirpe & $\begin{array}{c}\mathrm{N} \mathrm{da} \\
\text { parte aérea } \\
(\mathrm{mg})\end{array}$ & $\begin{array}{l}\text { Matéria seca } \\
\text { total } \\
\text { (g) }\end{array}$ & $\begin{array}{l}\text { Massa de } \\
\text { nódulos } \\
\text { secos }(\mathrm{g})\end{array}$ & $\begin{array}{c}\text { ARA } \\
\left(\mathrm{nmol} \mathrm{mL}{ }^{-1}\right.\end{array}$ \\
\hline BR3262 & $293,27 \mathrm{a}$ & $8,66 a$ & $0,62 \mathrm{a}$ & $53,08 \mathrm{a}$ \\
\hline BR3267 & $288,24 a$ & $9,55 \mathrm{a}$ & $0,89 \mathrm{a}$ & $69,59 \mathrm{a}$ \\
\hline BR2001 & $250,12 \mathrm{ab}$ & 7,39abc & $0,37 \mathrm{ab}$ & $28,26 \mathrm{ab}$ \\
\hline BR3280 & $239,58 \mathrm{abc}$ & $6,41 \mathrm{abcd}$ & $0,49 \mathrm{ab}$ & $29,04 a b$ \\
\hline BR3288 & $239,17 a b c$ & 7,74ab & $0,87 \mathrm{a}$ & $56,67 \mathrm{a}$ \\
\hline BR3287 & $218,83 \mathrm{abcd}$ & $6,96 a b c$ & $0,71 \mathrm{a}$ & 47,69ab \\
\hline BR3286 & 206,88abcd & 6,58abcd & $0,66 \mathrm{a}$ & $47,07 a b$ \\
\hline BR3278 & $198,53 \mathrm{abcd}$ & 5,97abcd & $0,45 \mathrm{ab}$ & $42,46 a b$ \\
\hline BR3284 & 133,93 abcde & e 5,82 bcde & $0,63 \mathrm{a}$ & $27,18 \mathrm{~b}$ \\
\hline BR3283 & $124,70 \mathrm{bcde}$ & 4,55 bcde & $0,26 b$ & $37,27 \mathrm{ab}$ \\
\hline BR3282 & $118,06 \mathrm{bcde}$ & $5,86 \mathrm{abcde}$ & $0,70 \mathrm{a}$ & $40,71 \mathrm{ab}$ \\
\hline BR3281 & 93,28 bcde & $3,41 \mathrm{de}$ & $0,31 \mathrm{ab}$ & $42,11 \mathrm{ab}$ \\
\hline BR3277 & $78,52 \mathrm{cde}$ & $3,68 \mathrm{cde}$ & $0,22 b$ & $38,66 a b$ \\
\hline BR3279 & $71,17 \mathrm{de}$ & $2,66 \mathrm{de}$ & $0,31 \mathrm{ab}$ & $40,47 \mathrm{ab}$ \\
\hline BR3285 & $56,60 \mathrm{de}$ & $1,93 \mathrm{de}$ & $0,22 b$ & $34,88 \mathrm{ab}$ \\
\hline $25 \mathrm{mg}$ de $\mathrm{N}$ & 57,15 de & 4,51 bcde & - & - \\
\hline Controle (S/I) & $5,39 \mathrm{e}$ & $0,87 \mathrm{e}$ & - & - \\
\hline$\overline{\mathrm{CV}}(\%)$ & 20,86 & 40,11 & 24,50 & 21,15 \\
\hline
\end{tabular}

${ }^{(1)}$ Valores seguidos da mesma letra não diferem significativamente a 5\% de probabilidade, pelo teste de Tukey; os dados de $\mathrm{N}$ total da parte aérea foram transformados para raiz quadrada.
Quanto à produção de matéria seca, os tratamentos com inoculação das estirpes BR3262 e BR3267 também apresentaram produção pelo menos $15 \%$ maior que o tratamento com a estirpe BR2001; no entanto, os valores foram significativamente superiores apenas aos tratamentos com as estirpes BR3285, BR3279, BR3277 e BR3281.

Quanto à massa de nódulos secos, as estirpes BR3262 e BR3267 apresentaram valores significativamente superiores às estirpes BR3277, BR3283 e BR3285; os demais tratamentos não apresentaram diferenças significativas.

Poucas diferenças também foram observadas na ARA; apenas a estirpe BR3284 apresentou atividade da nitrogenase significativamente inferior aos valores observados nos tratamentos com as estirpes BR3262 e BR3267.

Esses dados mostram que, embora a massa de nódulos secos e ARA tenham tido pouca diferença entre as estirpes, o acúmulo de $\mathrm{N}$ e a produção de matéria seca indicam a presença de estirpes com grande potencial como inoculante. Neste sentido, as estirpes BR3262 e BR3267 se destacaram por apresentar médias significativamente superiores ao tratamento nitrogenado e iguais à da estirpe BR2001, em todas as variáveis analisadas. Em termos absolutos, proporcionaram acúmulo de $\mathrm{N}$ e produção de matéria seca da parte aérea cerca de 15\% superiores. Essas duas estirpes já haviam sido estudadas anteriormente, quando também apresentaram bons resultados (Zilli et al., 1999; Martins et al., 2003). A estirpe BR3267, isolada de solo do SemiÁrido nordestino (Martins, 1996), está em fase de avaliação da eficiência na Relare, para validação da recomendação como inoculante para caupi no Nordeste brasileiro. Em experimento de campo, Martins et al. (2003) observaram que ela proporcionou produtividade semelhante à testemunha nitrogenada, em áreas de sequeiro com baixo aporte de fertilizantes. Quanto à estirpe BR3262, Zilli et al. (1999) observaram que a inoculação desta estirpe no caupi, referida no trabalho como E7-6, ocasionou um acúmulo de $\mathrm{N}$ e matéria seca pelo menos igual ao da estirpe BR2001, em experimento de casa de vegetação.

Observa-se, freqüentemente, que estirpes de B. japonicum contribuem para maior acúmulo de $\mathrm{N}$ na soja, comparadas às estirpes de B. elkanii (Santos et al., 1996). Este fato é atribuído à presença da enzima hidrogenase, ativa na associação B. japonicum/soja 
(Santos et al., 1996), e ao elevado número de nódulos fisiologicamente inativos, no caso de B. elkanii (Boddey \& Hungria, 1997). Neste trabalho, não se dosou a atividade da enzima hidrogenase, nem se avaliou o estado fisiológico dos nódulos; entretanto, não houve diferenças quanto à eficiência simbiótica entre estirpes de B. elkanii e Bradyrhizobium sp., o que demonstra existirem estirpes, independentemente da espécie, com potencial para uso como inoculantes para o caupi.

No experimento para avaliação da ocupação nodular, em condições de campo, estimou-se uma população de rizóbio no solo de $6 \times 10^{3}$ células $\mathrm{g}^{-1}$. Nestas condições, a taxa de ocupação nodular das plantas de caupi, avaliada por reação de Elisa (Figura 2), mostrou que as estirpes BR3287, BR3288 e BR3262 formaram mais de $60 \%$ dos nódulos, taxa significativamente superior às observadas para as estirpes BR2001 e BR3278. A estirpe BR2001 formou menos de 10\% dos nódulos, enquanto BR3278 não foi detectada. Observou-se, também, que os anti-soros das estirpes BR3267, BR3288 e BR3280 reagiram positivamente com 8, 35 e 60\% dos nódulos do controle, respectivamente.

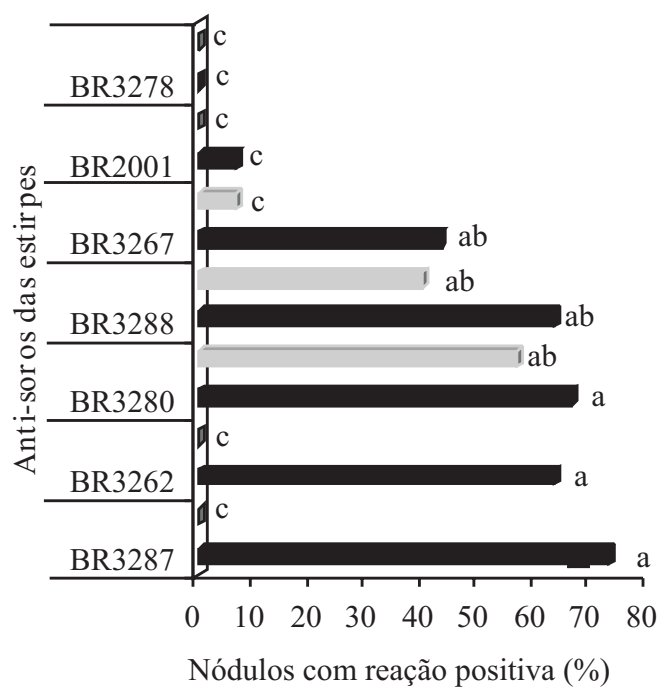

Inoculado Controle

Figura 2. Porcentagem de nódulos com reação positiva, avaliada por reação de Elisa, utilizando-se anti-soros policlonais. Valores seguidos das mesmas letras não diferem, significativamente, pelo teste de Tukey, a 5\% de probabilidade. A análise estatística foi realizada com os dados reais e não com as porcentagens. O coeficiente de variação foi 30,01\%.
A estirpe BR2001, recomendada até recentemente para a inoculação em caupi, apresenta bons resultados em casa de vegetação; entretanto, experimentos de campo indicaram dificuldade de estabelecimento da nodulação por esta estirpe (Martins, 1996; Zilli et al., 1999). Os dados obtidos neste trabalho confirmam esta observação uma vez que, em casa de vegetação, a estirpe BR2001 apresentou bom desempenho, mas foi incapaz de estabelecer nodulação no campo. As estirpes BR3287 e BR3262, no entanto, apresentaram alta competitividade, mesmo havendo uma população de rizóbio já estabelecida. As estirpes BR3280, BR3288 e BR3267 também apresentaram alta competitividade, porém o fato de ter ocorrido reação com nódulos do controle limita a conclusão e sugere que estas estirpes ou seus soro-grupos já estejam estabelecidos.

Na cultura da soja, tem se observado que B. elkanii é capaz de promover maior nodulação do que B. japonicum (Neves \& Rumjanek, 1997). Isto é atribuído à sua maior adaptabilidade às condições adversas dos solos tropicais (Boddey \& Hungria, 1997; Neves \& Rumjanek, 1997). Entretanto, os dados obtidos mostram que não houve diferença na nodulação promovida por estirpes identificadas como B. elkanii (estirpes BR3262, BR3280 e BR2001) ou como Bradyrhizobium sp. (estirpes BR3267, BR3278, BR3288 e BR3287) (Figura 2). Isto sugere que a capacidade de competir na formação de nódulos, em plantas de caupi, com a população de rizóbio estabelecida, não é uma característica de apenas uma espécie de Bradyrhizobium, mas de estirpes capazes de se adaptarem às condições edafoclimáticas onde estão sendo introduzidas (Coutinho et al., 1999; Hungria \& Vargas, 2000; Ferreira \& Hungria, 2002).

Associando-se os resultados de eficiência simbiótica e ocupação nodular, observa-se que as estirpes BR3262, BR3267, BR3280, BR3287 e BR3288 apresentaram bom desempenho, e são potenciais inoculantes para o caupi em solo de Cerrado do Nordeste brasileiro. Contudo, existe a necessidade da avaliação da contribuição dessas estirpes para a FBN e para a produtividade de caupi em condições de campo.

\section{Conclusões}

1. Das estirpes isoladas do solo de Cerrado, sete pertencem à espécie Bradyrhizobium elkanii, identificadas pelo seqüenciamento do $16 \mathrm{~S}$ rDNA. 
2. As estirpes BR3262 e BR3280 (Bradyrhizobium elkanii), e BR3267, BR3287 e BR3288 (Bradyrhizobium sp.), são potenciais inoculantes para o caupi, em razão do bom desempenho quanto à eficiência simbiótica e ocupação nodular.

3. Não existe diferença quanto à eficiência simbiótica e ocupação nodular entre estirpes de Bradyrhizobium elkanii ou Bradyrhizobium sp.

\section{Referências}

BEZERRA, A.A. de C. Variabilidade e diversidade genética em caupi (Vigna unguiculata, L. Walp.) precoce, de crescimento determinado e porte ereto e semi-ereto. 1997. 105p. Dissertação (Mestrado) - Universidade Federal Rural de Pernambuco, Recife.

BODDEY, L.H.; HUNGRIA, M. Phenotypic grouping of Brazilian Bradyrhizobium strains which nodulate soybean. Biology and Fertility of Soils, v.25, p.407-415, 1997.

CHEN, W.X.; TAN, Z.Y.; GAO, J.L.; LI, Y.; WANG, E.T. Rhizobium hainanense sp. nov., isolated from tropical legumes. International Journal of Systematic Bacteriology, v.47, p.870-873, 1997.

CHEN, W.X.; YAN, G.H.; LI, J.L. Numerical taxonomic study of fast-growing soybean rhizobia and a proposal that Rhizobium fredii be assigned to Sinorhizobium gen. nov. International Journal of Systematic Bacteriology, v.38, p.392-397, 1988.

COUTINHO, H.L. da C.; KAY, H.E.; MANFIO, G.P.; NEVES, M.C.P.; RIBEIRO, J.R.A.; RUMJANEK, N.G.; BERINGER, J. Molecular evidence for shifts in polysaccharide composition associated with adaptation of soybean Bradyrhizobium strains to the Brazilian Cerrado soils. Environmental Microbiology, v.1, p.401-408, 1999.

DE-POLLI, H.; FRANCO, A.A. Inoculação de sementes de leguminosas. Seropédica: Embrapa-UAPNPBS, 1985. 31p. (Embrapa-UAPNPBS. Circular técnica, 1).

EHLERS, J.D.; HALL, A.E. Cowpea (Vigna unguiculata (L.) Walp.). Field Crops Research, v.53, p.187-204, 1997.

FERREIRA, M.G.; HUNGRIA, M. Recovery of soybean inoculant strains from uncropped soils in Brazil. Field Crops Research, v.79, p.139-152, 2002.

FRED, E.B.; WAKSMAN, S.A. Laboratory manual of general microbiology, with special reference to the microorganisms of the soil. New York: McGraw Hill, 1928. 145p.

FREIRE FILHO, F.R.; RIBEIRO, V.Q.; BARRETO, P.D.; SANTOS, C.A.F. Melhoramento genético de Caupi (Vigna unguiculata (L.) Walp.) na Região do Nordeste. In: QUEIROZ, M.A.; GOEDERT, C.O.; RAMOS, S.R.R. (Ed.). Recursos genéticos e melhoramento de plantas para o Nordeste brasileiro. Petrolina: EmbrapaCPATSA; Brasília, DF: Embrapa-Cenargen, 1999. Não paginado. Disponível em: <http://www.cpatsa.embrapa.br/catalogo/livrorg/ index.html>. Acesso em: out. 2005.

HUNGRIA, M.; FRANCHINI, J.C.; CAMPO, R.J.; GRAHAM, P.H. The importance of nitrogen fixation to soybean cropping in South America. In: WERNER, D.; NEWTON, W.E. (Ed.). Nitrogen fixation in agriculture, forestry, ecology, and the environment. Dordrecht: Springer, 2005. p.25-42.

HUNGRIA, M.; VARGAS, M.A.T. Environmental factors affecting $\mathrm{N}_{2}$ fixation in grain legumes in the tropics, with an emphasis on Brazil. Field Crops Research, v.65, p.151-164, 2000.

JORDAN, D.C. Transfer of Rhizobium japonicum, Bucchanan 1980 to Bradyrhizobium gen. nov., a genus of slow-growing, root nodule bacteria from leguminous plants. International Journal of Systematic Bacteriology, v.32, p.136-139, 1982.

KUYKENDALL, L.D.; SAXENA, B.; DEVINE, T.E.; UDELL, S.E. Genetic diversity in Bradyrhizobium japonicum Jordan 1982 and a proposal for Bradyrhizobium elkanii sp. nov. Canadian Journal of Microbiology, v.38, p.501-505, 1992.

LAJUDIE, P. de; WILLEMS, A.; POT, B.; DEWETTINCK, D.; MASTROJUAN, G.; NEYRA, M.; COLLINS, M.D.; DREYFUS, B.; KERSTERS, K.; GILLIS, M. Polyphasic taxonomy of rhizobia: emendation of the genus Sinorhizobium and description of Sinorhizobium meliloti comb. nov., Sinorhizobium saheli sp. nov., and Sinorhizobium teranga sp. nov. International Journal of Systematic Bacteriology, v.44, p.715-733, 1994.

LIAO, C.F.H. Devarda's allow methods for total nitrogen determination. Soil Science Society of America Journal, v.45, p.852-855, 1981.

MAGUE, T.H.; BURRIS, R.H. Reduction of acetylene and nitrogen by field-grown soybeans. New Phytologist, v.71, p.275-286, 1972.

MARTINS, L.M.V. Características ecológicas e fisiológicas de rizóbios de caupi (Vigna unguiculata (L.) Walp) isolados a partir de solos da região Nordeste do Brasil. 1996. 213p. Dissertação (Mestrado) - Universidade Federal do Rio de Janeiro, Seropédica.

MARTINS, L.M.V.; XAVIER, G.R.; RANGEL, F.W.; RIBEIRO, J.R.A.; NEVES, M.C.P.; MORGADO, L.B.; RUMJANEK, N.G. Contribution of biological nitrogen fixation to cowpea: a strategy for improving grain yield in the Semi-Arid Region of Brazil. Biology and Fertility of Soils, v.38, p.333-339, 2003.

MOREIRA, F.M.S.; SIQUEIRA, J.O. Microbiologia e bioquímica do solo. Lavras: Universidade Federal de Lavras, 2002. 625p.

NEVES, M.C.P.; RUMJANEK, N.G. Diversity and adaptability of soyben and cowpea rhizobia in tropical soils. Soil Biology and Biochemistry, v.29, p.889-895, 1997.

REIS, V.M.; CRUZ, G.B.; FERREIRA, A.; FERREIRA, M.; FERREIRA, A.C.; REIS, F.B.; RIBEIRO, J.R.A.; SALLES, J.F.; WEBWER, O.P. Produção e caracterização de soros policlonais para a detecção de bactérias diazotróficas. Seropédica: EmbrapaCNPAB, 1997. 9p. (Embrapa-CNPAB. Documentos, 30).

RIBEIRO, J.R.A. Aplicação da técnica de ELISA no estudo ecológico de Rhizobium sp. isolados de nódulos de caupi (Vigna unguiculata (L.) Walp.) originários da Região Nordeste brasileira. 1999. 120p. Dissertação (Mestrado) - Universidade Federal do Rio de Janeiro, Rio de Janeiro.

SANTOS, V.A.F.; NEVES, M.C.P.; RUMJANEK, N.G. Efficiency of soybean nodules related to rhizobia hydrogenase is influenced by light level. Revista Brasileira de Fisiologia Vegetal, v.8, p.15-21, 1996. 
TEANEY III, G.B.; FUHRMANN, J.J. Soybean response to nodulation by bradyrhizobia differing in rhizobitoxine phenotype. Plant and Soil, v.145, p.275-285, 1992.

VINCENT, J.M. A manual for the pratical study of root nodules bacteria. Oxford: Blackwell Scientific, 1970. 164p.

WANI, S.P.; RUPELA, O.P.; LEE, K.K. Sustainable agriculture in the semi-arid tropics through biological nitrogen in grain legumes. Plant and Soil, v.174, p.29-49, 1995.

WOOMER, P.L. Most probable number counts. In: WEAVER, P.W.; ANGLE, J.S.; BOTTOMLEY, P.S. (Ed.). Methods of soil analysis. Madison: Soil Science Society of America, 1994. p.59-79.

XAVIER, G.R. Estudo da ocupação nodular de genótipos de caupi (Vigna unguiculata) agrupados pela técnica de RAPD. 2000. 113p. Dissertação (Mestrado) - Universidade Federal Rural do Rio de Janeiro, Seropédica.

YOUNG, J.P.; DOWNER, H.L.; EARDLY, B.D. Phylogeny of the phototrophic rhizobium strain BTAiL by polymerase chain reaction- based sequencing of a 16S rRNA gene segment. Journal of Bacteriology, v.173, p.2271-2277, 1991.

ZILLI, J.E. Caracterização e seleção de estirpes de rizóbio para a inoculação de caupi (Vigna unguiculata (L.) Walp.) em áreas de Cerrado. 2001. 112p. Dissertação (Mestrado) - Universidade Federal Rural do Rio de Janeiro, Seropédica.

ZILLI, J.E.; FERREIRA, E.P.B.; NEVES, M.C.P.; RUMJANEK, N.G. Efficiency of fast-growing rhizobia capable of nodulating cowpea. Anais da Academia Brasileira de Ciências, v.71, p.553560, 1999.

ZILLI, J.E.; NEVES, M.C.P.; RUMJANEK, N.G. Signalling specificity of rhizobia isolated from nodules of Phaseoleae and Indigofereae tribes. Anais da Academia Brasileira de Ciências, v.70, p.743-750, 1998.

ZILLI, J.E.; VALISHESKI, R.R.; FREIRE FILHO, F.R.; NEVES, M.C.P.; RUMJANEK, N.G. Assessment of cowpea rhizobium diversity in Cerrado areas of Northeastern Brazil. Brazilian Journal of Microbiology, v.35, p.281-287, 2004.

Recebido em 20 de junho de 2005 e aprovado em 3 de novembro de 2005 